\title{
85 km Long Reach PON System Using a Reflective SOA-EA Modulator and Distributed Raman Fiber Amplification
}

Tafur Monroy, Idelfonso; Öhman, Filip; Yvind, Kresten; Kjær, Rasmus; Peucheret, Christophe; Koonen, A.M.J.; Jeppesen, Palle

Published in:

IEEE Lasers \& Electro-Optics Society

Link to article, DOI:

10.1109/LEOS.2006.278927

Publication date:

2006

Document Version

Publisher's PDF, also known as Version of record

Link back to DTU Orbit

Citation $(A P A)$ :

Tafur Monroy, I., Öhman, F., Yvind, K., Kjær, R., Peucheret, C., Koonen, A. M. J., \& Jeppesen, P. (2006). 85 km Long Reach PON System Using a Reflective SOA-EA Modulator and Distributed Raman Fiber Amplification. In IEEE Lasers \& Electro-Optics Society (pp. 705-706). IEEE. https://doi.org/10.1109/LEOS.2006.278927

\section{General rights}

Copyright and moral rights for the publications made accessible in the public portal are retained by the authors and/or other copyright owners and it is a condition of accessing publications that users recognise and abide by the legal requirements associated with these rights.

- Users may download and print one copy of any publication from the public portal for the purpose of private study or research.

- You may not further distribute the material or use it for any profit-making activity or commercial gain

- You may freely distribute the URL identifying the publication in the public portal 


\title{
$85 \mathrm{~km}$ long reach PON system using a reflective SOA-EA modulator and distributed Raman fiber amplification
}

\author{
Idelfonso Tafur Monroy (1,2), Filip Öhman (1), Kresten Yvind (1), Rasmus Kjær (1), \\ Christophe Peucheret (1), A.M.J Koonen (2), and Palle Jeppesen (1) \\ 1) COM•DTU, Department of Communications, Optics and Materials, Technical University of Denmark, 2800 Kgs. Lyngby, Denmark \\ 2) Eindhoven University of Technology, 5600 MB Eindhoven, The Netherlands (i.tafur@tue.nl)
}

\begin{abstract}
We report on a bidirectional $85 \mathrm{~km}$ long reach PON system supported by distributed fiber Raman amplification with a record $7.5 \mathrm{~Gb} / \mathrm{s}$ remote carrier modulated upstream signal by employing a reflective SOA-EA monolithically integrated circuit.
\end{abstract}

\section{INTRODUCTION}

In fiber-to-the-customer premises networks, cost effective solutions for both the optical network units (ONUs) at the customer premises and the optical access feeder are of crucial importance. The use of carrier re-modulation at the customer terminal rather than a local light source has been suggested as a way of reducing installation and maintenance costs by avoiding stabilization and provisioning issues associated with a local laser [1,2]. Regarding the optical access feeder, the concept of long reach access network has been introduced which aims at building a high split passive optical network (PON) architecture with high capacity and extended reach (over $80 \mathrm{~km}$ ) to merge optical access and metro networks into a single system $[3,4]$. Commonly, the backhaul link of the above systems uses two fibers (one each for upstream and downstream communication between the core node and the local exchange) supported by optical amplification by using erbium doped fibre amplifiers (EDFAs). Future access networks will need to accommodate the constantly growing demand for capacity, both for the up and downstream channel, and data speeds in the order of $10 \mathrm{~Gb} / \mathrm{s}$ are foreseen, e.g. due to the introduction of Gigabit Ethernet solutions. Therefore, solutions for ONUs supporting high bit-rates will be needed while still satisfying the stringent cost-effective requirements.

We report on a long reach access system, see Figure 1, whose backhaul link is composed of a single fiber by introducing bidirectional communication, supported by distributed Raman fiber amplification. Moreover, our proposed long reach system employs a remote carrier modulator at the ONU that avoids the need for a local laser source at the customer premise. We show experimentally the feasibility for remote carrier modulation at a bit-rate up to $7.5 \mathrm{~Gb} / \mathrm{s}$ by using a novel monolithically integrated reflective modulator comprising a concatenated semiconductor amplifier (SOA) and an electro-absorber (EA) section: R-SOA-EA. Transmission over a bidirectional $80 \mathrm{~km}$ long backhaul link supported by distributed Raman amplification introduces a power penalty below $0.4 \mathrm{~dB}$.

\section{EXPERIMENTAL SETUP}

The experimental set-up is shown in Fig. 2. A continuous wave (CW) generated by a DFB laser source $\lambda_{1}$ at a $1553.3 \mathrm{~nm}$ wavelength is directed via an optical circulator towards the ONU over a span of $5.7 \mathrm{~km}$ of standard single mode fiber

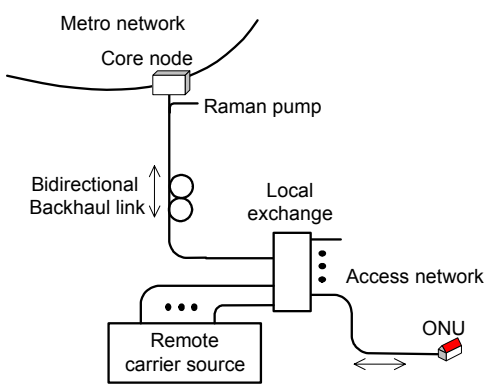

Figure 1. Extended reach access system with single fiber. Bidirectional backhaul link and distributed Raman fiber amplification.

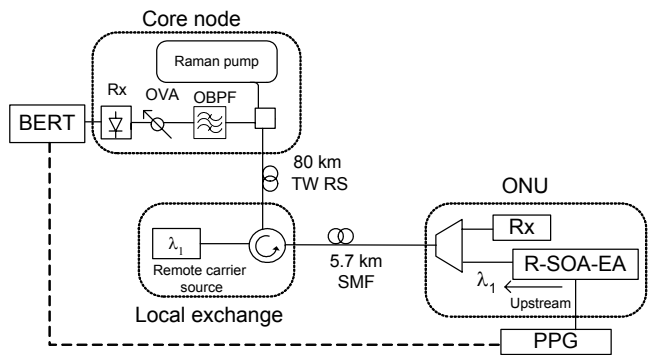

Figure 2. Experimental setup. PPG: pulse pattern generator. BERT: bit-error rate test set. Rx: optical direct detection receiver.

(SMF). The remote carrier source can be located at the central node or alternatively at the local exchange as illustrated in Fig. 1. At the ONU, the EA section of the R-SOA-EA chip is directly modulated by a $2^{31}-1$ pseudorandom bit sequence (PRBS) derived form a pulse pattern generator (PPG). This modulated signal is used as the upstream channel that is first transmitted to the local exchange and subsequently propagates towards the core node over a link of $80 \mathrm{~km}$ of TrueWave ${ }^{\mathbb{R}}$ reduce slope (TWRS) optical fiber with a measured loss of $16.3 \mathrm{~dB}$ and a total dispersion of $400 \mathrm{ps} / \mathrm{nm}$ at $1550 \mathrm{~nm}$. Raman distributed fiber amplification (DRFA) is used to compensate for the transmission loss and to allow for a large wavelength and/or power splitting ratio at the local exchange. The pump signals were at the wavelength $1437.2 \mathrm{~nm}$ and $1464.5 \mathrm{~nm}$ with corresponding power levels of $22.0 \mathrm{dBm}$ and $22.30 \mathrm{dBm}$, respectively. The Raman pump on-off gain is measured to be $13.9 \mathrm{~dB}$. DRFA offers bidirectionality, wide wideband operation with high OSNR values [5]. At the core node an optical bandpass filter (OBPF) with a 3-dB bandwidth of $0.3 \mathrm{~nm}$ is used to reject spontaneous emission noise (ASE) from the R-SOA-EA device. The optical receiver $(\mathrm{Rx})$ uses no optical pre-amplification.

\section{R-SOA-EA MODUlATOR DESIGN AND FABRICATION}

A photograph and schematic layout of the fabricated R-SOA-EA component are shown in Fig. 3. The device 
consists of a waveguide separated in two sections defined by the top electrodes shown in the figure. The SOA and EA sections are $300 \mu \mathrm{m}$ and $45 \mu \mathrm{m}$ long, respectively. The waveguide is bent in order to have one facet with high and one with low reflection. The two facets are also coated with high and anti-reflection coatings, respectively. The active material consists of eight, compressively strained, $7.0 \mathrm{~nm}$ thick InGaAsP quantum wells in a strain compensated structure and is the same for both sections.
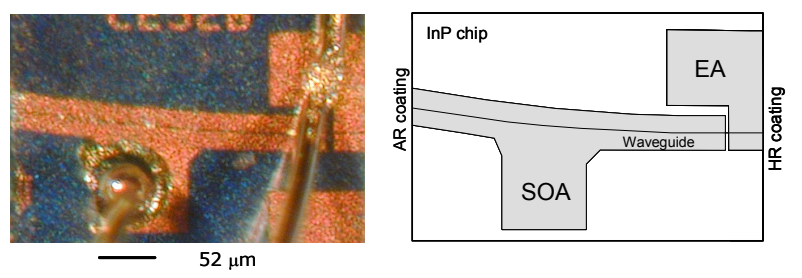

Figure 3. Photograph and schematic layout of the reflective semiconductor electro-absorption (R-SOA-EA) modulator.

\section{RESULTS}

Coupling to the R-SOA-EA chip is realized by using a tapered fiber. The coupling loss is estimated to be $3 \mathrm{~dB}$. The average input power to the pigtail that connects to the R-SOA-EA was set to $2.7 \mathrm{dBm}$ and kept fixed through the experiments reported here. A polarization controller was used to align the state of polarization of the signal at the input of the chip. Although, the current chip under study shows both polarization dependent operation and requires a relative high input optical power lever, superior performance of this device can be achieved by optimizing the waveguide geometry and the use of tensile strain material to increase the polarization insensitivity. Moreover, fiber pigtailing and packaging would provide better power coupling efficiency and temperature stable operation. The average output power from the R-SOA-EA was measured to be $4 \mathrm{dBm}$ for a SOA bias current of $100 \mathrm{~mA}$, and the bias of the EA section set to zero Volt. Modulation is achieved by direct modulation of the bias voltage applied to the EA section of the R-SOA-EA device with a bias voltage of $0.25 \mathrm{~V}$ and signal amplitude of $1.5 \mathrm{~V}_{\mathrm{pp}}$. The average input power level at the input to the $80 \mathrm{~km}$ TWRS fiber link (at the local exchange after transmission over $5.7 \mathrm{~km}$ of SMF) is measured to be around $0 \mathrm{dBm}$. The back-to-back configuration is referred to the case where the $5.7 \mathrm{~km}$ of SMF is removed. Figure 4 presents the eye-diagram of the modulated signal by using the R-SOA-EA chip for bit-rates at $5 \mathrm{~Gb} / \mathrm{s}$ and $7.5 \mathrm{~Gb} / \mathrm{s}$, respectively, at different points of the setup shown in Figure 2. The measured extinction ratio for the $5 \mathrm{~Gb} / \mathrm{s}$ and $7.5 \mathrm{~Gb} / \mathrm{s}$ were $11.6 \mathrm{~dB}$ and $9.5 \mathrm{~dB}$, respectively. These bit-rates are higher than those reported with conventional reflective SOA modulators that are in the order of $1.25 \mathrm{~Gb} / \mathrm{s}[1]$.

Figure 5 shows the results of the bit-error rate measurements. The left curves at Figure 5 correspond to the case of $5 \mathrm{~Gb} / \mathrm{s}$. We can observe that a receiver sensitivity penalty at a bit-error rate of $10^{-9}$ of $0.7 \mathrm{~dB}$ is incurred at the local exchange with respect to the back-to-back configuration. Transmission over the $80 \mathrm{~km}$ TWRS link introduces a power penalty of only 0.3 $\mathrm{dB}$. For the case of $7.5 \mathrm{~Gb} / \mathrm{s}$, Figure 5 (right), the power penalty at the local exchange with respect to back-to-back is $1.3 \mathrm{~dB}$. However, transmission over the $80 \mathrm{~km}$ TWRS links introduces a power penalty of only $0.4 \mathrm{~dB}$.

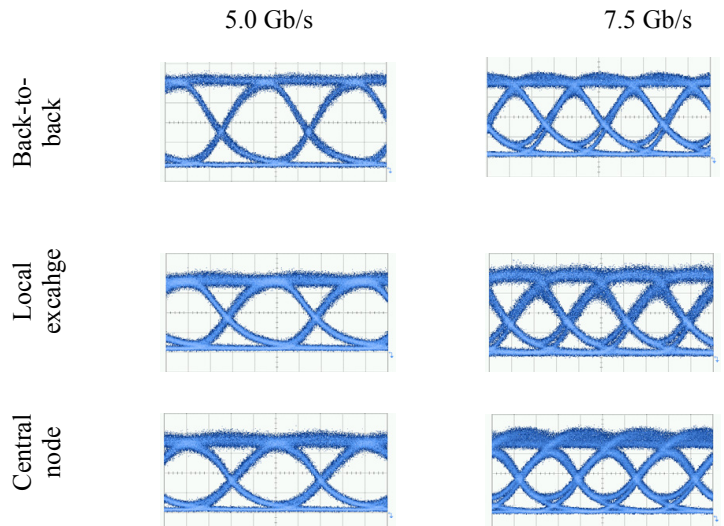

Figure 4. Eye-diagrams for the upstream signal at different point of the systems for a modulated signal at $5 \mathrm{~Gb} / \mathrm{s}$ and $7.5 \mathrm{~Gb} / \mathrm{s}$ by employing a reflective semiconductor electro-absorption (R-SOA-EA) modulator.

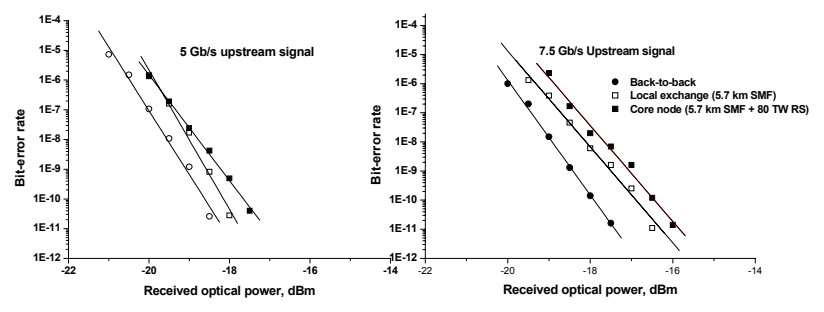

Figure 5. Bit-error rate measurement results for an upstream signal at $5 \mathrm{~Gb} / \mathrm{s}$ (left) and $7.5 \mathrm{~Gb} / \mathrm{s}$ (right). Signal modulation is imposed by using a reflective semiconductor electro-absorption (R-SOA-EA) modulator.

\section{CONCLUSION}

We have successfully demonstrated remote carrier modulation at bit-rates up to $7.5 \mathrm{~Gb} / \mathrm{s}$ by using a R-SOA-EA monolithically integrated circuit. Error-free transmission over a link with a total length of $85 \mathrm{~km}$ with no observable power penalty and without dispersion compensation is reported by employing distributed fiber Raman amplification. The proposed link is an attractive solution for simplified high bitrate, bidirectional, long-reach PON systems.

\section{ACKNOWLEDGMENT}

This work was supported by the post-doctoral grant program of the Villum Kann Rasmussen Fund. The R-SOA-EA chip was fabricated within the SCOOP project funded by the Danish Technical Research Council.

\section{REFERENCES}

[1] J. Prat et al., IEEE PTL, 17, pp. 250-252 (2005).

[2] W. Lee et al.,M. IEEE PTL, 17, pp. 2460-2462 (2005).

[3] D. B. Payne et al., BT Technol J. (2002), pp.104-114.

[4] R. P. Davey, et al., IEEE/OSA J LT, 24 (2006) pp. 29-31.

[5] I. Tafur Monroy et. al., paper We3.P.166, ECOC 2006. 